\title{
TO DETERMINE THE EFFECTIVENESS OF COGNITIVE BEHAVIORAL GROUP THERAPY ON THE RATE OF CHANGE IN DEPRESSION AND MENTAL HEALTH OF HIGH SCHOOL STUDENTS
}

\author{
Maryam Mohammadi Toraghi \\ Department of Psychology, Kish International Branch, Islamic Azad University, Kish Island, Iran \\ Farhad Jomehri \\ Phd of Psychology, Department of Psychology, Kish International Branch, Islamic Azad University, \\ Kish Island, Iran \\ Afshin Tayebi \\ Assistant Professor, Faculty Islamic Azad University of Karaj
}

\begin{abstract}
This study aimed to determine the effectiveness of cognitive behavioral group therapy on depression and the rate of change of mental health of high school students. The research model of this study is quasi-experimental and is applied research due to the objective component. A research project was for two groups of experimental group and control group, with pretest and posttest. The population of this study included all high school students (male and female) in Tehran. Given that the study population was high school students, the sample of this study consisted of 30 high school students who were accidentally classified into the two groups (15 in experimental group, 15 in control group). A tool that is used in this study is Beck Depression Inventory (B.D.I) and mental health of Keys. Information collected were prepared for statistical calculations; after gathering and removing the defects at the end of it, all data collected were entered into SPSS Inferential statistics (for the difference between the experimental group and the control group) test multivariate analysis of covariance (ANCOVA) was used, the results indicate that all four hypotheses were accepted.
\end{abstract}

Keywords: cognitive therapy, depression, mental health, high school students

\section{INTRODUCTION}

Adolescence is a period of change that constitutes usually ages 13 to 19 and is undoubtedly one of the most important periods of the individual. In this age, changes are concerned in the adolescent growth and development of relations between different aspects. These changes include: attachment, independence (change the relationship with parents, siblings), intimacy (formation of close personal relationships outside the family), development (skills and roles required for life), identity (sense of composition and role of emotions children with demands and benefits of adults). The events cause many mental disorders including depression (Safarpur, 2006). Given that the prevalence of depression among children is on the rise, this study aimed to investigate the usefulness of cognitive therapy on depression and mental health of high school students. The results of this study may help experts to identify therapeutic strategies in the treatment of depression and mental health.

\section{DEFINING MENTAL HEALTH}

So far, various definitions of "mental health" provided that all the characters have emphasized the importance of integrity. Goldstein knows the mental health member balance between and environment to achieve self-actualization. Chahn, (1991) interprets the mental health status of psychological maturity that means the maximum effectiveness and satisfaction derived from the individual and social opposition including emotions and positive feedback about themselves and others. (Ganji, 2005) In recent years, the Canadian Association of Mental Health has defined "mental health" in three parts: 
THE FIRST PART: SELF-FEEDBACK INCLUDES:

1. Mastery of self-emotions.

2. being aware of self- weaknesses.

3. Satisfaction of self- pleasures.

PART II: FEEDBACK ON OTHERS INCLUDES:

1. Interest on long and intimate friendship.

2. A sense of belonging to a group.

3. Human and material responsibility to the environment.

\section{PART III: FEEDBACK ON LIFE INCLUDES:}

1. Bear the responsibilities.

2. Tasteful facilities and interests development.

3. Ability to personal decisions.

Taste of good work (Maslow, 1996, translated by Rezvani, 1993).

Chahn has mentioned five patterns of behavior in relation to mental health:

1. Sense of accountability: who has mental health, is sensitive to the needs of others and to satisfy them and makes them comfortable as well.

2. Self- confidence: who has mental health, has self-confidence and ensures his ability to process cross-sectional problems. Thus, obstacles, compromised not affect his morale.

3. Goal orientation: refers to a person who possesses a clear concept of the ideal of life and hence, will lead all the force and creativity in order to achieve these goals.

4. Personal values: such a person in his life has a particular philosophy based on opinions, beliefs and goals of prosperity and happiness to themselves or those around him to take a lead and to increase social participation.

5. individuality and Oneness: a person who has mental health does not know himself distinct from the others, and is trying to develop the attitudes and their behavior patterns in a way that is neither blind conformity and unconsciously demands and desires of others and not by others is rejected and abandoned.

\section{DEFINING DEPRESSION}

1. Depression is an emotional state with sorrow that the person feels the guilt or sin with fear and emptiness. (Haidari, 2002). The first and major character of depression is sadness that may fluctuate from a mild to frustration, despair and severe distress. The mood change is relatively constant and is continuing for days, weeks, months or years. Depression as a symptom of many physical and mental diseases may be a state of grief and mourning but the difference detector of depression is such that it is inappropriate and depression is a very severe and long lasting disease. Depression in these patients affects all aspects of emotion and thought, behavior the person, personality and interests. Apart from that there's always anxiety and depression, in which the patient complained of discomfort, the motor restlessness is expressed in the form of physical discomfort or lack of appetite and sleep disorders and the reactions were mild and acute depression and confusion could be divided into three major categories.

\section{TYPES OF DEPRESSION}

- Depression is a reactive created as a result of the emergence of adverse situations. 
- Secondary depression emerges as a result of some physical ailments or partial lack of experience.

- The third type of depression cannot be diagnosed with the internal origin where there is no apparent cause will be favorable answer to physical therapy.

- A fourth type can also be added to the three types of depression, and it is pessimism that the patient invariably sees everything around the dark adverse events and is always waiting foir bad news and events. The most notable hidden depressive symptoms in children have been reported as: behaviors such as delinquency, hypochondriasis, irritability and hyperactivity, bowel dysfunction, fear, truancy and school problems (Renshaw, 1974, Carlson and Cantwell, 1983, Sarason and Sarson, 1987, quoted from Aali, 2008).

\section{GROUP COUNSELING WITH COGNITIVE APPROACH}

In general, the main emphasis in Counseling Psychology is within individual skills in order to cope with the pressures of life. Counseling Psychology use different methods to treat their clients as diverse as psychotherapy, workshops to teach skills like assertiveness, self-expression, social skills and utilize them in order to objectify the evaluation of their psychological aptitude tests, attitudes, interests, personality and so on (Guregil, 2001). In the process of consultation the person may be treated due to the type of individual, group, or with his family. In the case of children and adolescents have many effects and group counseling can help them to better understand and prevent internal conflict and to strengthen positive interpersonal relationships. In understanding and solving the problems of children, consultants face with serious problems. The adult common way to communicate with others is used for children. They may cut off talk with a counselor or his friend by screaming, refuse to carry out the activities that the adviser recommends or to participate very lively, active and with high sensitivity in group activities. In group therapy, teenagers find that others have problems similar to their problems and obstacles are reduced in the way of expressing inner feelings. The teenager finds a sense of belonging to the group and interpersonal skills growing in dealing with real life. Through trial and error, teenager learns appropriate ways to communicate with others. After a while, the group is seen as a model for the society for Teen. Because many teenagers are required to communicate with peers, group counseling is very effective to solve their problems, because in groups that engages young people is created in the right environment in order to plan their problems. Children in the support group discover that they are not only teenagers that have such problems; other teenagers also have the like. In organized group consultation, many young people are discovering that they can get help from others to solve their problems and participate in solving other problems. Thus, they experience effectiveness, and self-value and realize that they are unique and wholeheartedly accepted by their peers in the group. According to Corder, Whiteside and Heizlip (1981) youth will learn in the group consultation process: 1) express their feelings; 2) assume responsibility for their words and deeds, 3) ask others their opinion honestly; 4) group is considered as a big family, and 5) are able to help others and be involved in their lives.

\section{COGNITIVE THERAPY, PATTERN AND EFFICIENCY}

Structure: Cognitive therapy is a method of psychotherapy based on the theory of emotional disorders (Beck, 1967), experimental and clinical studies (coax and Becky, in 1987, King Bern Black, 1988), as well as certain therapeutic techniques. This organized form of psychotherapy treatment is to reduce symptoms and help the person to learn effective ways to deal with problems that are causing discomfort he designed. Features of treatment with this method are all efforts that are focused on solving the problem.

Cognitive therapy is working on a complex set of problems psychologically and a situation that may involve upsetting the person. The term "cognitive therapy" is used because the therapeutic techniques are used in order to change one's mistakes and cognitive biases among those who try to assess individual situations and psychological pressure, his views about themselves, the world and the next and the beliefs and attitude are modified that appears to increase vulnerability to emotional disorders. As noted above, this treatment approach is based on historical contexts, theoretical and empirical. 
Application: the cognitive strategies are used to help clients to solve any problems, such as malfeasance in connection with the thought patterns (Perstoniz, Bronze, 1986), generalized anxiety (Lindsey et al., 1987), addiction to alcohol (Nathan, 1985), extreme emotional distress (McAdam, 1986), psychopathic behavior (Kazdin et al., 1987), drunk driving (Segal and Moore, 1985), negative body image (far Kane and chorus, 1985) behavioral responses of individual coronary arteries (Razi et al., 1986, 1987), anger (Diffen buffer et al.), bulimia (Qyrberton et al., 1986), attention deficit disorder (Berlon et al., 1986).

\section{COGNITIVE BEHAVIORAL COGNITIVE FEATURES}

It is organized, collaborative, voluntary and limited in time. The emphasis will be on the current situation or the present and placed full attention the role of belief or knowledge incorrect and inconsistent. This treatment is based on the fundamental premise that thoughts, emotions and actions are linked together and cognitive distortions are found in the conclusions and can be eliminated through their learning this way, we had to explain characteristics (Mehryar, 1994).

Organized: each meeting and all the meetings are of the high degree of organization and discipline. The meetings are organized such that the person's estimation is at the center of attention. Then, the sick behavior is at the center of psychologist's attention and finally recognizing automatic thoughts or assumptions whether as a substrate, they are evaluated as a treatment goal. The person is expected to have a home assignment planning that must be done regularly participate in meetings away. These tasks in turn-based self-help reflect primary emphasis on assessment, then finally the recognition of individual behavior.

Individual participation: in cognitive approach, the psychologist and the individual both participate in the initial assessment and treatment program flow measuring efficiency. Cognitive psychologist tries to make person to participate at all stages, including the subject matter of any meeting or view the actual notes by individual behaviors, arranging activities and vognitive behavioral tasks to the stage of putting the assumption that the company actively.

Socrates: It insists on questioning of individual and in this way, the person will help to discover and express new content. It will try to speak the language or the interpretation or assumptions about the meaning of individual speech conversely refused to personally help him to discover the meaning and the behavior and utterances success. The cognitive approach is usually a wise Socratic method instead of questioning and discussion for questioning and for his opposition defied belief.

Experimental or optional: training a person to think clearly and his belief will be tested experimentally, is one of the main objectives of the cognitive approach. Often the person is encouraged to use his conduct testing of a belief or faith.

The emphasis on the present: the individual and psychologist attention is focused often on issues and topics that have already or are raised here and now to the individual. The emphasis on the past generally is not necessary for the purpose of changing individual symptoms and required skills of the individual, through an experimental approach (Mehryar, 1994).

In terms of time: the duration is 20 sessions of cognitive-behavioral training. Usually begins with two sessions per week and later reduced to one session per week.

Emphasis on knowledge: the cognitive approach puts the emphasis on analysis and evaluation of one's thoughts instead of his emotions, but emotions are typic11111111ally cognitive, and psychologists are of interest, but they are treated them as if their existence and durability depend on ideas and preceding beliefs. Cognitive Psychology in dealing with clients who with negative emotions rather than the expressions of sympathy and support not only stressed, tries to help them to get away from these beliefs related to negative emotions and assess if they are realistic and unsentimental.

Cognitive distortions are a result of learning: In general, it is assumed that people based on their previous experiences achieve thought and specific belief patterns. Obviously, if we talk quite carefully, it is not necessary to accept the premise. What is necessary is the content or process 
(thoughts and beliefs) through treatment change. The automatic thoughts and assumptions foundations are believed to be learned through practical experience and encounter either directly or indirectly or second-hand, and both more specific and tangible aspects are more automatic thoughts and it is thought to be easier to change (Kaplan, translation Pour Afkari, 1993).

Behavioral-cognitive: at the beginning of each session will highlight the discussion cases, assigns some exercises for implementation within certain meetings and teaches new skills. Psychologist and people work together. Cognitive- behavioral has three components: educational aspect, cognitive techniques and behavioral techniques (Kaplan, Inc. Pourafkari, 1993).

1. Educational aspect: the educational aspect involves explaining Therian cognitive schemas and logic's wrong. Psychologists must explain to the assumptions set together and will put to the test during their treatment. Cognitive therapy involves a complete description of the relationship between depression and anxiety with thinking, emotions and behavior, as well as the philosophy of all aspects of the treatment. This explanation contradicts the analysis-oriented psychotherapy that requires very little explanation.

1. Cognitive techniques: methodology includes a four-step process: 1. disclose non-adaptive automatic thoughts 2 . Testing automatic thoughts hidden assumptions, 3. Identify non-adaptive, 4. Testing the validity of hypotheses. Automatic recognition includes thoughts between external events and specific emotional reactions toward them. An example of automatic thoughts is the belief that when others see how clumsy I am playing, everyone will laugh at me. Thought that crosses anyone's mind that bowling has been invited and has shown a negative reaction. Automatic thoughts are also called cognitive-called transformation. Each pathologic profiles psychotic disorder, especially cognitive thinking is changing by the day dedicated to recognizing the template, if known.

2. Behavioral techniques: are cognitive techniques or behavioral techniques. Behavioral techniques are used for testing non-adaptive cognitive impairment or improperly. The overall goal is to help the person to understand the false assumptions of their cognitive and learning new techniques to cope with its consequences.

role playing and recreational methods can be named between behavioral techniques used for planning activities, domination and determine cognitive tasks step by step exercises, self-reliance training (Kaplan, Inc. of Pourafkari, 2000).

Behavioral techniques: behavioral techniques can often be used in treatment because the problems that can be treated with these techniques may be a very uncomfortable one and prevent the development of treatments. Given these problems, it is vital to examine Group Cognitive Therapy on Depression and the mental health of high school students.

\section{METHODOLOGY}

This study used a quasi-experimental research model and according to the purpose is an applied research. A research project consists two groups and the control group was accompanied by pretest and posttest. The population of this study included all high school students (male and female) in Tehran. Given that the study population was high school students, the sample consisted of 30 students in high school that were randomly divided into two groups (15 in experimental group, 15 in control group). A tool that is used in this study includes Beck Depression Inventory (B.D.I) and mental health of Keys. In the first step by visiting the Department of Education in Tehran, "the theoretical and technical assistance" list of names was prepared for girls and boys high school. Then, a girl and a boy high school were selected randomly, and Beck depression with mental health questionnaire of Keys on high school students and was conducted $(\mathrm{n}=213$ high school girls and 114 people in high school), then the total students of secondary schools, 30 of those had acquired the highest scores on the depression scale and also had the lowest scores on a scale mental health were selected for the study. They then randomly divided into two groups: control and experimental groups. Before starting group therapy sessions, the pre-test was conducted for both groups. Then the experimental involvement, namely, the cognitive group counseling in collaboration with the participants in the intervention conducted. During this trial period, the control group did not receive any intervention. In this case, the data collected were prepared for statistical calculations; after gathering the questionnaires and 
removing the defects at the end of it, all data collected were entered into SPSS Inferential statistics (for the difference between the experimental group and the control group) the multivariate analysis of covariance (ANCOVA) was used.

\section{DATA ANALYSIS:}

\section{DESCRIPTIVE STATISTICS}

In boys, frequency in the experimental group ( $n=9,64.3$ percent) is more than the control group (5 patients, 35.7 percent). Frequency in girls in the control group $(\mathrm{n}=10,62.5$ percent $)$ is more than experimental group $(n=6,37.5$ percent), and also in total 14 patients (46.7 percent) are in the group of boys, and 16 people (53.3 percent) are in the group of girls.

\section{INFERENTIAL STATISTICS}

First hypothesis: cognitive behavioral group therapy has a significant impact on reducing depression among high school students.

Table 1. variable statistics in both control and experimental groups before and after intervention

\begin{tabular}{|c|c|c|c|c|c|c|}
\hline \multicolumn{2}{|c|}{ Post-test } & \multicolumn{2}{|c|}{ Pre-test } & \multirow{2}{*}{$\begin{array}{l}\text { Num } \\
\text { ber }\end{array}$} & \multirow{2}{*}{ Group } & \multirow{2}{*}{ Variable } \\
\hline SD & Mean & SD & Mean & & & \\
\hline $5 / 74$ & $25 / 40$ & $6 / 56$ & $31 / 27$ & 15 & $\begin{array}{l}\text { Experi } \\
\text { mental }\end{array}$ & Depression \\
\hline $4 / 74$ & $29 / 93$ & $5 / 68$ & $31 / 20$ & 15 & Control & \\
\hline
\end{tabular}

As can be seen, the mean of studied variables (depression) in the experimental group had a significant reduction in post-test but in the post-test in control group that there is a reduction, but this reduction does not seem much that needs to be examined.

For using analysis of covariance (ANCOVA) must be adhered to its assumption given that the pre-test and post-test scores are normalized to study the homogeneity of variances using Levin explains:

\begin{tabular}{cccc}
\multicolumn{4}{c}{ Levine test to check the homogeneity of variances } \\
\hline sig. & Degree of freedom 2 & Degree of freedom 1 & F \\
\hline $0 / 337$ & 38 & 1 & $\mathbf{0 / 9 5 3}$ \\
\hline
\end{tabular}

Table 3 and Figure 1 show the results of analysis of covariance (ANCOVA) to substantiate the research hypothesis (cognitive behavioral group therapy has a significant impact on reducing depression among high school students.).

Table 3. ANOVA test results for the hypothesis

\begin{tabular}{c|cccccc}
\hline $\begin{array}{c}\text { Effect } \\
\text { size }\end{array}$ & $\begin{array}{c}\text { Significance } \\
\text { level }\end{array}$ & F & $\begin{array}{c}\text { Mean } \\
\text { Square }\end{array}$ & $\begin{array}{c}\text { Degrees of } \\
\text { freedom }\end{array}$ & $\begin{array}{c}\text { Sum of } \\
\text { squares }\end{array}$ & \\
\hline $0 / 814$ & $0 / 0001$ & $117 / 875$ & $612 / 827$ & 1 & $612 / 828$ & Pre-test \\
$0 / 577$ & $0 / 0001$ & $36 / 800$ & $191 / 323$ & 1 & $191 / 323$ & Group \\
& & & $5 / 199$ & 27 & $140 / 372$ & Error \\
\hline
\end{tabular}




\section{0

The results of analysis of covariance (ANCOVA) revealed that cognitive behavioral group therapy used in a study of high school students in the pre-test and post-test sizes $0 / 814$ and 0/577 caused a reduction in depression in the experimental group effect size sample group of students $(0 / 05>p$, $117 / 875=\mathrm{F})$ and $(0 / 05>\mathrm{p}, 36 / 800=\mathrm{F})$. Pre-test and post-test charts are shown for both control and experimental groups below.

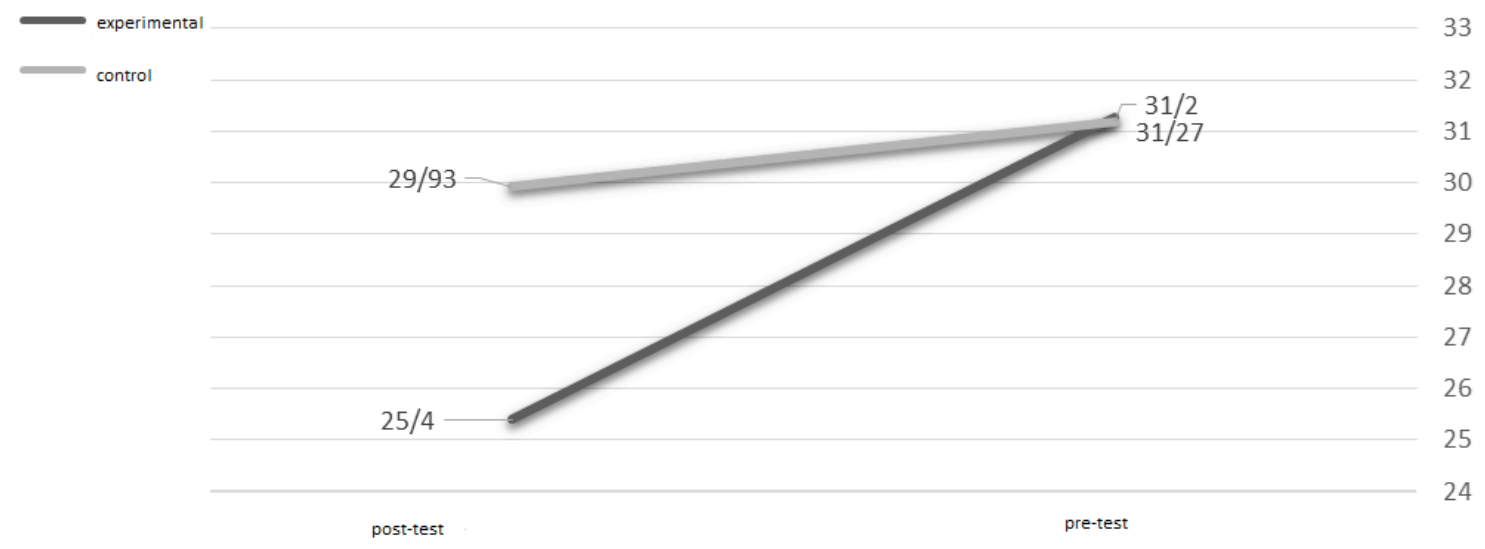

the scores of depression pre- \& post-test of experimental \& control groups

Transactional Analysis group counseling approach used by the sample group is to increase self-esteem in students.

\section{The second hypothesis: cognitive behavioral group therapy has a significant impact on the} mental health of high school students.

Table 4. Variable statistics in both control and experimental groups before and after intervention

\begin{tabular}{|c|c|c|c|c|c|c|}
\hline \multicolumn{2}{|c|}{ Post-test } & \multicolumn{2}{|c|}{ Pre-test } & \multirow{2}{*}{$\begin{array}{l}\text { Num } \\
\text { ber }\end{array}$} & \multirow{2}{*}{ Group } & \multirow{2}{*}{ Variable } \\
\hline SD & Mean & SD & Mean & & & \\
\hline $4 / 79$ & $35 / 87$ & $4 / 74$ & $29 / 93$ & 15 & $\begin{array}{l}\text { Experi } \\
\text { mental }\end{array}$ & \multirow[t]{2}{*}{$\begin{array}{l}\text { Mental } \\
\text { health }\end{array}$} \\
\hline $4 / 17$ & $29 / 33$ & $4 / 79$ & $29 / 80$ & 15 & Control & \\
\hline
\end{tabular}

As can be seen variables investigated (Mental health) experimental group has increased significantly in the post-test but in the control group in the post-test not only did not increase, but decreased at trace levels that should be examined.

To test this hypothesis, the inferential analysis of covariance (ANCOVA) was used for the comparison of the effect Pre-test. Mental health scores at pre-test and post-test is normal and Levin to check the homogeneity of variances test results are shown in Table 8-4.

\section{Table 5 Levine test to check the homogeneity of variances}




\begin{tabular}{cccc} 
Significance & Degree of freedom 2 & Degree of freedom 1 & F \\
\hline $0 / 372$ & 28 & 1 & $\mathbf{0 / 8 2 5}$ \\
\hline
\end{tabular}

Table 6 and Figure 2 present the results of analysis of covariance (ANCOVA) to substantiate the research hypothesis (cognitive behavioral group therapy has a significant impact on the mental health of high school students.).

Table 6. ANOVA results for the hypothesis

\begin{tabular}{c|cccccc}
\hline $\begin{array}{c}\text { Effect } \\
\text { size }\end{array}$ & $\begin{array}{c}\text { Sig. } \\
\text { level }\end{array}$ & F & $\begin{array}{c}\text { Mean } \\
\text { square }\end{array}$ & $\begin{array}{c}\text { Degree of } \\
\text { freedom }\end{array}$ & $\begin{array}{c}\text { Sum of } \\
\text { squares }\end{array}$ & \\
\hline $0 / 831$ & $0 / 0001$ & $132 / 465$ & $469 / 392$ & 1 & $469 / 392$ & Pre-test \\
\hline $0 / 763$ & $0 / 0001$ & $86 / 940$ & $308 / 072$ & 1 & $308 / 072$ & Group \\
& & & $3 / 544$ & 27 & $95 / 675$ & Error \\
& & & & 30 & $32768 / 000$ & Total \\
\hline
\end{tabular}

The results of analysis of covariance (ANCOVA) revealed that cognitive behavioral group therapy used in a study of high school students in the pre-test and after the test, the size of 0/831 and 0/763 increased in the experimental group, and the effect size of mental health increased in the sample group $(0 / 05>\mathrm{p}, 132 / 465=\mathrm{F})$ and $(0 / 05>\mathrm{p}, 86 / 940=\mathrm{F})$.

Chart of pretest and post-test is shown for both control and experimental groups below.

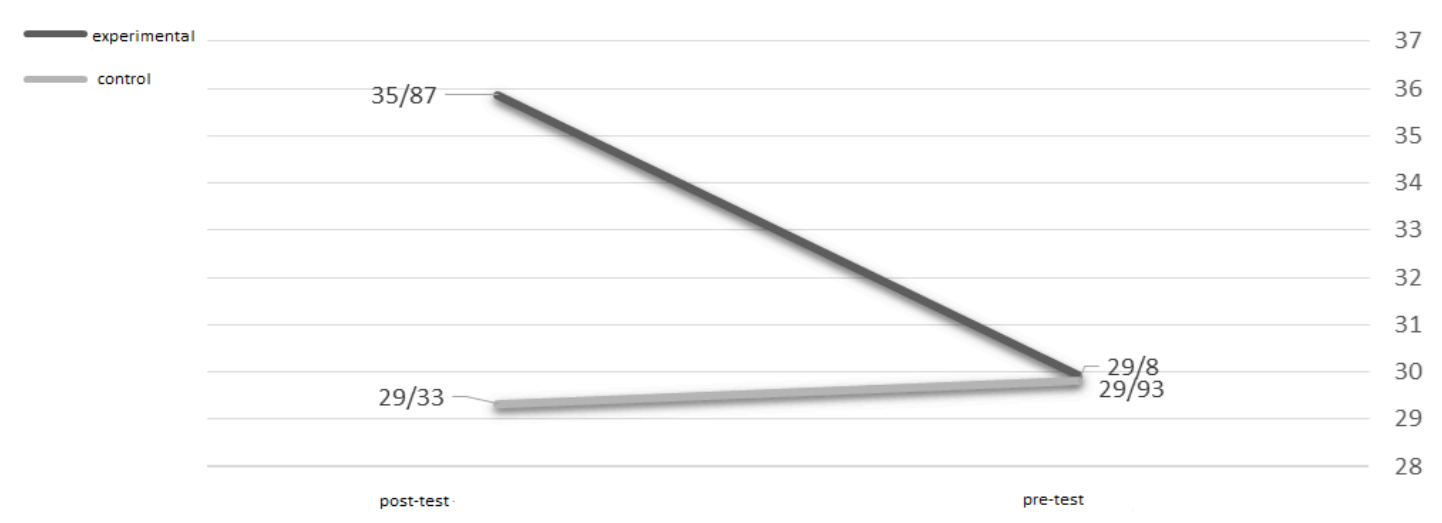

the scores of ment

Cognitive therapy is used to increase students' mental health in the sample.

Third hypothesis: the reduction of depression has a significant difference between boys and girls.

Table 7. statistics depression scores in the two groups of boys and girls after intervention

\begin{tabular}{lllll}
$\begin{array}{l}\text { Error of } \\
\text { standard }\end{array}$ & SD & Mean & Number & Gender \\
\hline
\end{tabular}

Submit Date: 21.06.2016, Acceptance Date: 26.07.2016, DOI NO: 10.7456/1060AGSE/031

Copyright $(C)$ The Turkish Online Journal of Design, Art and Communication 


\begin{tabular}{ccccc}
\hline deviation & & & & \\
\hline $\mathbf{2} / \mathbf{6 7}$ & $5 / 97$ & $32 / 80$ & 5 & Boys \\
$\mathbf{1 / 7 5}$ & $5 / 53$ & $29 / 200$ & 10 & Girls \\
\hline
\end{tabular}

As can be seen, variables studied (depression) in girls was lower than boys, which should be examined. To test this hypothesis in some independent $t$ test was used for comparison of mean:

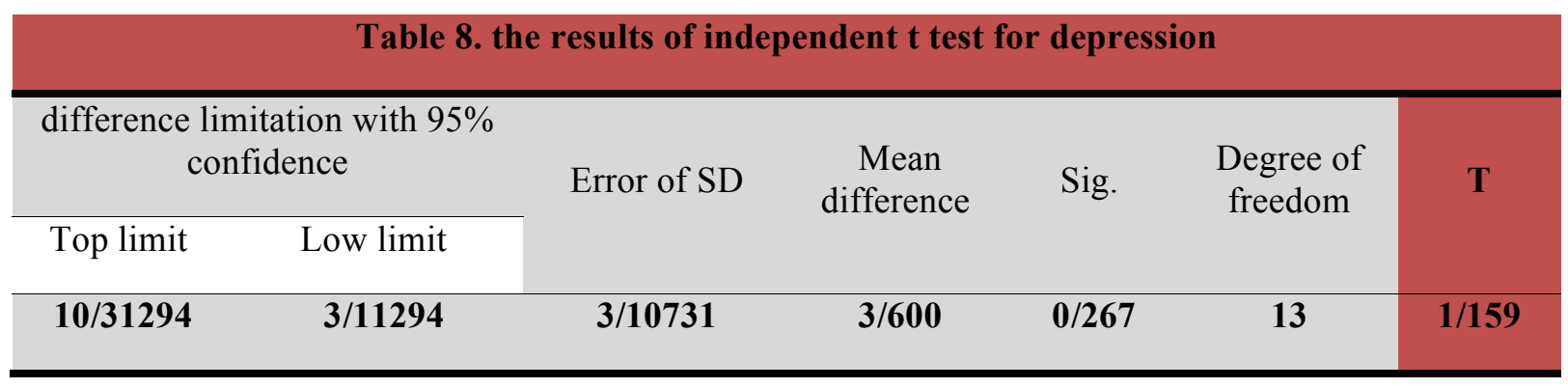

As can be seen in the table, although the rate of decline depression among girls is more than boys, but among girls $(5 / 53=\mathrm{SD}$ and $29 / 200=\mathrm{M})$ and boys $(5 / 97=\mathrm{SD}$ and $32 / 80=\mathrm{M})$ there was no significant difference in decreasing depression $(-1 / 159=\mathrm{t}$ and $0 / 05>\mathrm{P})$.

\section{Fourth hypothesis: the increase of mental health has a significant difference between boys and} girls.

Table 9. statistics mental health scores in the two groups of boys and girls after intervention

\begin{tabular}{ccccc}
\hline Error of SD & SD & Mean & Number & Gender \\
\hline $\mathbf{1} / \mathbf{9 6}$ & $4 / 39$ & $26 / 60$ & 5 & Boys \\
$\mathbf{1} / \mathbf{1 1}$ & $3 / 50$ & $30 / 70$ & 10 & Girls \\
\hline
\end{tabular}

As can be seen, variables studied (mental health) in girls was higher than boys, which should be examined. To test the hypothesis in this part of the independent $t$ test was used to compare mean:

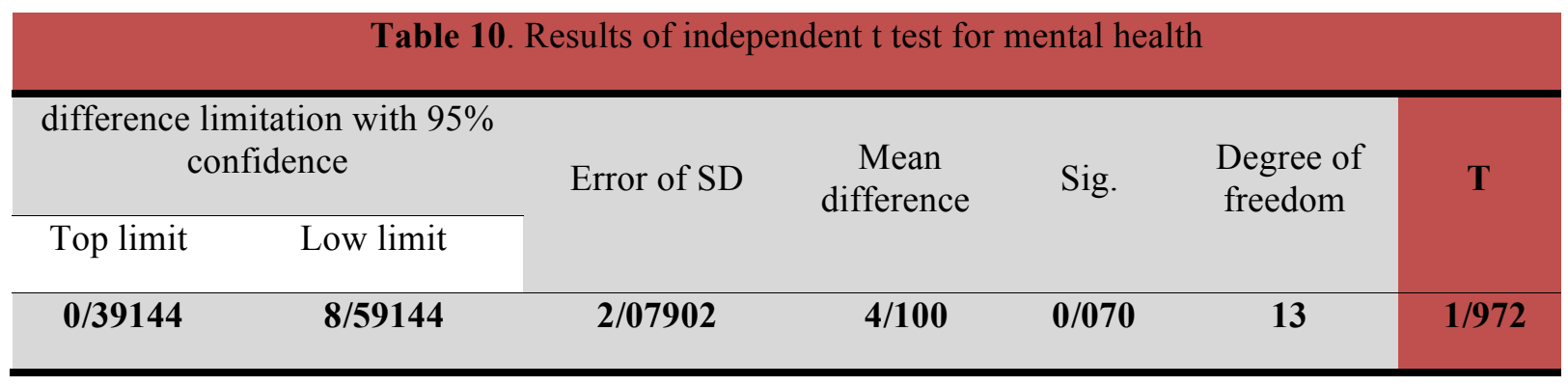


As can be seen in the table, although the girls' mental health was more than boys, but there is no significant difference between and boys $(-3 / 50=\mathrm{SD}$ and $-30 / 70=\mathrm{M})$ and boys $(-4 / 39=\mathrm{SD}$ and $60 / 26$ $=\mathrm{M})$ considering mental health $(-1 / 972=\mathrm{t}$ and $0 / 05>\mathrm{P})$.

\section{DISCUSSION AND CONCLUSION}

To interpret the results, first the data were described and results of the test research hypotheses were interpreted. Study descriptive information on relevant demographic characteristics of the samples indicate that distribution of boys and girls is normal and almost they have the same proportion of each study, but this is not the same than in the control and experimental groups so that girls were more than boys in the control group and boys were more than girls in the experimental group.

First hypothesis: cognitive behavioral group therapy has a significant impact on reducing depression among high school students.

The results of this study are in conjunction with the first hypothesis of Piekel, 2007 and Guidi 2010. It is shown that this method was effective in treating depression and its effects are comparable with antidepressants. The research showed that cognitive therapy on depression is more effective than drug therapy.

\section{The second hypothesis: cognitive behavioral group therapy has a significant impact on the mental health of high school students.}

The results of this study are in conjunction with the second hypothesis of the research of Vahedi et al (2003). In this study, it was shown that most students are suffering from mental disorders. The most common psychopathology studied populations were, respectively, aggression, depression, anxiety, obsessive-compulsive disorder, somatization disorder, phobia, psychosis and paranoia.

Third hypothesis: the reduction of depression has a significant difference between boys and girls.

The results in relation to the third hypothesis are consistent with the research that Rajabi and Kasmaee (2012) conducted to evaluate the effectiveness of counseling with the emphasis on rational-emotive behavioral therapy, the general health of male and female high school students in Ahvaz city in the third year.

\section{Fourth hypothesis: the mental health has a significant difference between boys and girls.}

The results in relation to the fourth hypothesis are consistent with research that have been conducted by Rajabi and Kasmaee (2012). The results showed that group counseling, increased component of general health, depression, anxiety, somatic complaints, and poor social functioning (male and female students in the experimental group. As a result of emotional - behavioral group therapy of Alice, in a way effective in reducing psychological signs and symptoms of male and female high school students, also no significant differences were found between reducing psychological symptoms between boys and girls.

\section{RECOMMENDATIONS}

$\checkmark \quad$ similar investigations in other countries with larger sample size and more generalized findings

$\checkmark \quad$ The use of cognitive therapy alone or with other methods of treating depression in teens

$\checkmark \quad$ Pay particular attention to depression in adolescents as national capital

$\checkmark \quad$ Cognitive psychology health education to students of psychology to help students, especially teenagers

$\checkmark \quad$ Other comparative study compared group CBT with medication

\section{REFERENCES}

Ganji, H., "mental health", 2005, Arasbaran publication Co.

Robbins, S. (2004) Principles of Organizational Behavior. Translated by Arabi, Seyyed Mohammadi. 
Ross Mitchell, translation: Ravandoost, V. - Astan Quds Razavi, cultural deputy. According to the website project

Rajabi, GR, Karjo Kasmaei, S, (2012), the effectiveness of group counseling with rational, emotional, behavioral and public health on the components of the boys and girls, Journal of School Psychology, Summer, Volume I, Number 2 / 76-59

Rio, Marshall. Motivation and excitement. (2003), Translation by Seyyed Mohammadi, Tehran: Edit. According to the website project

Houghton, K. (2006) cognitive behavioral therapy, translated by Ghasemzadeh, Tehran: Arjmand publication Co.

Henry Masson, P., (1991), children's personality development, translation: Mahshid Yasayy- First Edition, Tehran, Press Paya. According to the website project

Hooman, HA., "multivariate data analysis in behavioral research", 2006, Tehran, recreation and culture.

Yahgoobi Nasr abadi, MK., Atef, V., and Ahmad zadeh, Gh. (2003), "The Influence of Cognitive Behavioral Group Therapy on Depression and Anxiety in Patients with Mood Disorder", Journal of thought and behavior, the ninth year.

Saffarpour RA. Comparison of the level of depression and emotion in girl teenagers residing at boarding schools and other girl teenagers [dissertation]. Shahid Beheshti Univ;2006.

Cloninger, C.R. (2004). "Feeling good: the science of well-being". New York:oxford PressUniversity DeRubeis RJ, Gelfand LA, Tang TZ, Simons AD. Medication versus cognitive-behavioral therapy for several depressed outpatients: Mega analysis of four randomized comparisons. American Psychiatric 1999;156,7:1007-100

Ferri M. Cognitive Therapy in Groups: Guildlines and Resources for Practice. New York: John Wiley \& Sons; 1999.

Free ML. Cognitive therapy in groups: Guidelines and resources for practice. New York: Jon Wiley \&sons, Inc.;1990.

Gorji S. A study of the prevalence of depression and the effect of group cognitive therapy on reducing depression amount the boy students of the high schools and technical schools of district 1 of Gharchak [dissertantion].Tarbiat Moalem Univ.; 2001. 31.

Guidi GA, Fava M, Papakostas GI. Efficacy of the sequential integration of psychotherapy and pharmacotherapy in major depressive disorder: a preliminary meta-analysis. Psychological Medicine 2010;41(2):321-331.

Jex, S. M., \& Bliese,(1999) Efficacy beliefs as a moderator of the impact of work-related

stressors":A multilevel study. Journal of Applied Psychology

Locke, E. A., \& Latham, G. P. (1990). A theory of goal setting and task performance. Englewood Cliffs, NJ: Prentice Hall.

Maddux, J.E. (1991). Self-efficacy. In C.R. Snyder. \& D.R. Forsyth. Handbook of Social and Clinical Psychology (pp. 57-78). New York: Pergamon Press. 